\title{
Factors That Promote Remission in Individuals with Schizophrenia
}

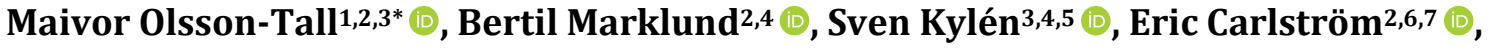 \\ Lars Helldin ${ }^{1,8}$, Siv Bäck-Pettersson 4 (1) \\ ${ }^{1}$ Department of Psychiatry, NU-Health Care Hospital, Trollhättan, Sweden \\ ${ }^{2}$ Academy of Sahlgrenska, Institute of Medicine, University of Gothenburg, Gothenburg, Sweden \\ ${ }^{3}$ Centre on Health Care Improvement and Innovation, Chalmers University of Technology, Gothenburg, Sweden \\ ${ }^{4}$ Närhälsan Research and Development Primary Health Care, Region Västra Götaland, Sweden \\ ${ }^{5}$ Fyrbodal Health Academy, County Administration of West Sweden, Sweden \\ ${ }^{6}$ Academy of Sahlgrenska, Institute of Health and Care Sciences, University of Gothenburg, Gothenburg, Sweden \\ ${ }^{7}$ University of South-East Norway, Westfold, Norway \\ ${ }^{8}$ Institute of Psychology, Karlstad University, Karlstad, Sweden \\ Email: *maivor.olsson-tall@vgregion.se
}

How to cite this paper: Olsson-Tall, M., Marklund, B., Kylén, S., Carlström, E., Helldin, L. and Bäck-Pettersson, S. (2019) Factors That Promote Remission in Individuals with Schizophrenia. Open Journal of Nursing, 9, 935-950.

https://doi.org/10.4236/ojn.2019.99070

Received: August 4, 2019

Accepted: September 7, 2019

Published: September 10, 2019

Copyright $\odot 2019$ by author(s) and Scientific Research Publishing Inc. This work is licensed under the Creative Commons Attribution International License (CC BY 4.0).

http://creativecommons.org/licenses/by/4.0/

\begin{abstract}
The knowledge about factors contributing to remission among individuals with schizophrenia is still missing. Studies show that the number of individuals' reaching remission is varying among psychiatric outpatient care centres. Therefore, the purpose was to investigate case managers (CM) perception of care interventions promoting remission. Semi-structured interviews were conducted with CM $(\mathrm{n}=12)$ and data were analysed with qualitative content analysis. The results show that CM needs to possess competence, master assessment structure and process. These key-points appear to be of crucial importance for a successful promotion of remission among individuals with schizophrenia.
\end{abstract}

\section{Keywords}

Assessment, Case Managers, Remission, Teamwork, Schizophrenia

\section{Introduction}

Knowledge on how to give the right support to people with schizophrenia is still greatly needed. Even if care interventions have been associated with setbacks, there are still promising ongoing clinical activities. One example of such activities is the regular use of assessments that seem to promote remission and improve case managers' capability to collaborate [1]. In this study, case managers 
(CMs) were interviewed from a clinic that proved to be successful in the care of mental illness. The purpose was to identify potential interventions that promoted remission.

Schizophrenia is the most serious form of mental illness; it affects people worldwide. About 25 million suffer from schizophrenia, which has a major impact on a person's life and their loved ones [2] [3] [4]. The disease causes great human suffering and requires extensive efforts by society in the form of various support measures [5] [6]. In Sweden alone, the total cost amounts to EUR 62,500 per individual per year for the care of schizophrenia [7].

Common symptoms that affect the individual's daily life with schizophrenia are, for example, hallucinations and delusions. In addition, impaired memory and impaired executive functions are often present, negatively affecting the ability to communicate [8] [9] [10]. The main obstacle is stigmatization and poorly treatment by the public. Individuals with mental illness are marginalised and discriminated in the community. Suffering from an impaired function can be vulnerable to negative social attitudes [11]. On the other hand, an improved function can enhance the individual's self-confidence and develop psychosocial skills [12]. Although diagnosis and symptoms are the focus, there is an increasing interest in whether the function is affected by the symptoms. The individuals' function is mainly affected by their status and the environment [13]. In addition, the illness often involves repeated episodes of impairment [14].

Empowerment is regarded to recover by building up capacities for an active and autonomous life and improved self-confidence. Empowered individuals with schizophrenia can take charge, make decisions and take initiatives. Remission is a collective term for clarifying qualitative goals for individuals with schizophrenia. One criterion for remission is that the function not be affected even though symptoms are present [15].

In clinical assessments, the individual, as a reporting agent, is one of the most important sources of information. Self-estimates can have a beneficial effect on function by increasing the individual's self-awareness [16]. However, there are problems with self-assessment due to impaired neurocognitive ability. In a cross-sectional study [17], it appears that individuals' self-assessment is not congruent with the assessment that the trained CMs conduct with evidence-based assessment instruments.

Within outpatient psychiatric care, it is common to appoint a CM who has the main responsibility for the contact with the individual, who performs assessments and who meets the needs of the individual [18]. Repeated assessments made by a CM, with subsequent conversations in dialogue as an equal partner with the individual, increase the prerequisites for clarifying the needs that need to be addressed [1] [19]. It has been shown that supportive conversations have a positive influence on the individual's self-confidence, which leads to increased ability to handle daily life [20].

CMs are also responsible for initiating internal and external collaboration with relevant healthcare providers to assist with individual support measures 
[21]. Despite individual differences in ability and social skills, it has been shown that targeted support efforts in this way improve the ability of individuals with schizophrenia to improve in function and empowerment [18].

For CMs to be able to assess remission, the individual needs to signal their experiences. To communicate one's needs is a challenge especially when coming to symptoms, perceptions, thoughts and feelings [17]. Orlando's [22] nursing theory has been used as a source of inspiration for this study, for analyses of reflection and communication between the individual, relatives and care team. Based on Orlando's [22] theory, it is important that CMs remain objective when, for example, how an individual's behaviour in different situations is to be interpreted. CMs role is to integrate with the individual and perceive the needs that should be met. A starting point in this study is that when such a dynamic relationship is established, the possibility of making common contributions that can benefit remission increases.

Several studies show that a lower level of function, i.e. when individuals are not in remission, affects the experiences of both everyday life and care [2] [23]. When the symptoms increase, not only is the function affected, it can also cause suffering to the individual and creates the risk of shorter life. In addition, hospital admissions increase [21] [24]. Previous research studies have, however, shown that among the individual diagnosed with schizophrenia, a proportion between $33 \%$ [25] to $38 \%$ [26] achieve remission.

This study has been carried out at a Swedish psychiatric clinic with 10 in-patient facilities and nine out-patient units. The out-patient units have shown promising results, in terms of the number of individuals' who have achieved remission. In a long-term follow-up, the Clinical Long-term Investigation of Psychosis in Sweden (CLIPS), it is shown that the number of individuals' who achieved remission had increased from 38\% to 54\% during the years 2000-2014. One probable reason for success may be a new way of working that was introduced in 2005 [1].

That year, annual assessment conversations were introduced at nine psychiatric out-patient clinics in the admission area. To identify symptoms, the Positive and Negative Syndrome Scale (PANSS) was used as a rating scale measure [8] [27] [28]. PANSS is the basis for the assessment of symptomatic remission, Remission scale for Schizophrenia-Symptoms (RS-S), which is based on eight of the 30 items on PANSS. With the rating scale RS-S, an assessment was made as to whether the symptoms were of such a degree that they affected the function or not, where the maximum value was assessed as being in remission [15] [27] [29].

The annual follow-up was considered to contribute to an increased understanding and a reduced knowledge gap between the CM and the individual. Since no other interventions were introduced, the repeated assessment conversation and the relationship that the CM built with the individual were considered as reasons for the results [1]. The results are, to the best of our knowledge, unique and are therefore worthy of in-depth studies. The purpose of this study 
was to identify CMs perceptions of factors that promote remission in individuals with schizophrenia.

\section{Materials and Methods}

\subsection{Design}

To gain knowledge about CMs perception of what in the psychiatric care promotes remission for individuals with schizophrenia, the study was conducted with a qualitative, inductive method. Informants were included strategically, based on the following criteria: that they had the knowledge and experience of working as a $\mathrm{CM}$ in psychiatric outpatient care in teams and independently conduct annual health assessments with validated instruments.

\subsection{Participants}

The study included CMs $(\mathrm{n}=12)$; women $(\mathrm{n}=7)$ and men $(\mathrm{n}=5)$ from the nine psychiatric outpatient units, representing both urban and rural areas. The ages varied between $52-71$ years. Professional years since undergraduate education varied between 23 - 49 years. Seven had educational background as registered nurses. Five had education in psychiatric nursing on advanced level. Five were trained as assistant nurse in psychiatric nursing, three of them had further training as therapists. The majority $(n=11)$ had worked for five years or more using the current method in psychiatric outpatient care.

\subsection{Data Collection}

The study was conducted in 2018. The data collection was planned together with the informant regarding time and place, either at their unit or the R \& D centre. The informants received oral and written information about background of the study, purpose, participation being voluntary, being able to withdraw from participation at any time, that the study material would be treated confidentially and used only for research purposes according to the [30]. The participants were given the opportunity to ask questions, and the signed consent was drawn up in duplicate. The first author of the study conducted all the interviews. Initially, a brief information text was read out so that all informants would have the same starting point at the commencement of the interview. The data collection was conducted with semi-structured interviews based on an interview guide that consisted of the following questions: Please describe your perception of what, except pharmacological treatment, promotes remission? Please describe a successful and less successful assessment interview with the patient? What is the difference between a support conversation and a structured assessment interview? How does the assessment interview affect team collaboration?

The interviews ended with the informants being asked if there was anything more that they wanted to add. After the first interview, a pilot analysis was done. The interviews lasted about 40 - 50 minutes, were recorded with dictaphone and transcribed verbatim. 


\subsection{Analysis}

The interviews were listened to several times and analysed with a qualitative method for content analysis, where both the manifest and latent contents were highlighted [31] [32]. After repeated readings of the transcribed texts, the text was divided into meaningful units. The meaningful units were condensed and coded. Thereafter, subcategories were formulated based on the text's manifest content; the codes were compared with respect to similarities and differences, and from the subcategories, three categories appeared. The authors discussed these based on the transcribed text. Finally, the overall theme was formulated. Table 1 gives example of the different steps of the analysis.

Table 1. Example of the different steps of the analysis process from meaning units, condensation, coding, subcategory to category.

\begin{tabular}{lcccc}
\hline Meaning units & Condensed meaning unit & Code & Subcategory & Category \\
\hline As these are my assessments, CM needs to know how to & "Know & $\begin{array}{c}\text { Methodological } \\
\text { professional }\end{array}$ \\
then, I, as the staff, need & use the instruments to & how" & competence \\
knowledge about the & conduct a proper & & \\
evaluation instruments, to be & assessment & \\
able to make the assessments. & & \\
It is the most important! & & \\
\hline
\end{tabular}

\subsection{Ethical Considerations}

The study was conducted in accordance with the Helsinki Declaration's research ethics guidelines [30] and is approved by the Ethics Review Board in Gothenburg 2010-07-05 [Diary number: 438-10]. Approval to carry out the study was obtained partly from the operations manager for out-patient psychiatric care and partly from the head of the respective unit. Participants were informed orally and in writing about the background, purpose, study implementation and were given the opportunity to ask questions. They were informed that participation was voluntary and could withdraw from the study at any time without any explanation. Informed consent was signed in two copies by those who wanted to participate [33] [34].

\section{Results}

The analysis revealed that annual assessment conversations using validated instruments promote remission in patients with schizophrenia in out-patient psychiatric care. The overall theme was formulated based on three categories and nine subcategories that highlighted the value of systematic assessment (Table 2).

\subsection{Professional Competence}

The analysis highlighted the specific competence that the informants believed that CMs need to have, to carry out an effective assessment conversation in the care of individuals with schizophrenia. On the question of what qualities were important for promoting remission, the informants believed that it required 
Table 2. Description of the study theme, categories and subcategories.

\begin{tabular}{|c|c|c|c|}
\hline \multirow{2}{*}{$\begin{array}{l}\text { Theme } \\
\text { Category }\end{array}$} & \multicolumn{3}{|c|}{$\begin{array}{c}\text { Annual assessment conversations using validated instruments promote remission in } \\
\text { patients with schizophrenia }\end{array}$} \\
\hline & Professional competence & Assessment structure & Assessment process \\
\hline \multirow[t]{3}{*}{ Sub-category } & $\begin{array}{l}\text { Psychiatric and } \\
\text { methodological knowledge }\end{array}$ & $\begin{array}{l}\text { Illuminates symptoms and } \\
\text { dysfunctions }\end{array}$ & Forms the basis for care \\
\hline & Alliance-generating ability & $\begin{array}{l}\text { Indicates the need for } \\
\text { contact and follow-ups }\end{array}$ & $\begin{array}{l}\text { Constitutes a common agenda } \\
\text { and communication channel }\end{array}$ \\
\hline & $\begin{array}{l}\text { Ability to individualise in } \\
\text { time and space }\end{array}$ & $\begin{array}{l}\text { Enables evaluation and } \\
\text { comparison of remission } \\
\text { status }\end{array}$ & $\begin{array}{l}\text { Promotes team collaboration } \\
\text { and care continuity }\end{array}$ \\
\hline
\end{tabular}

professional knowledge, an alliance-generating ability and ability to individualise in time and space. Professional knowledge included both knowledges in psychiatry as well as knowledge of assessment instruments and methodology.

"It is important that you have knowledge of mental illness. It is also important that you have knowledge about medicines, to have knowledge about society and what there are opportunities for development in society and about different types of care available." (Informant 8)

Regarding the assessment instruments, the informants pointed out that it was important to be familiar with the definitions and criteria that are included in each evaluation. In addition, they also highlighted the importance of having joint regular assessment exercises, so that these assessments will be carried out in the same way for all individuals' regardless of which psychiatric unit they visit.

"Knowledge of the assessment instruments is needed to be able to do assessments. Calibration of the evaluation knowledge is also needed through joint evaluation exercises with other CMs, in order to maintain quality." (Informant 2)

The informants thought that with knowledge as the basis and with experience of working in psychiatric care, they were better at "listening between the lines" and evaluating what the individual did not say.

"It is important with knowledge in psychiatry, to be able to ask further when one understands that something is not good." (Informant 2)

"It is important that you are sensitive to what and how the individuals' think about their medicines and whether they are motivated to take their medications. There are always those who know whether or not they have a problem with the drug so that they can be accommodated." (Informant 8)

When it comes to CMs ability to form an alliance generating approach, the informants described different ways of responding to individuals based on their function and personality. The importance of this approach was emphasised by several: 
"It is a respect for the individual that I must have, because there are many questions that go into many different areas." (Informant 1)

"All the time with the individual increases the possibility of an alliance, which can be important for an improvement." (Informant 2)

"I think it is based on if I get a good alliance with the individual, then we can also discuss why he comes here, the diagnosis, how it is treated and different options. If we have a good alliance it can be great conversation." (Informant 9)

Regarding CMs ability to individualise in time and space, the informants stressed the importance of preparation for the individuals' visit, about how the individual was called to the visit, where the visit would take place and the importance of performing mutual activities.

"To remove some of the stress, I ask the individual to suggest a place. Sometimes it may be that you have the assessment conversation at patient's home." (Informant 11)

"We meet with a certain regularity, where she always gets to decide when we will meet, according to her needs. It usually is every two weeks to every other month.” (Informant 8)

"It is also important to do some activities together; you can take a walk, do some study visits or go shopping. These are normal things that most of us do, but something that this patient group may not do so often. When you get to be a help engine, it can lead to something positive.” (Informant 5)

\subsection{Assessment Structure}

Assessment structure means the forms of assessment conversations and the design of the assessment instrument. The category includes the informants' perception of the importance that the assessment structure promotes remission. The assessment structure illuminates' symptoms and dysfunctions indicate the need for contact and follow-ups and, in addition, enable evaluation and comparison of remission status. These three areas were considered by the informants as essential to observe and capture variations in the individuals' functional or dysfunctional status.

"When the assessment conversation follows a structure, a template, then there is less risk of forgetting important questions. In a regular support conversation, one might wander into different directions." (Informant 11) "When you have the paper with the questions, it is easier to ask sensitive questions, such as the sexual, and the structure means a lot to both the individual and me. I can ask the questions objectively, and the individual can see it in another way, because it is in the manual. It is so!" (Informant 9) "I don't think about whether they are in remission or not when I sit down to have the conversation; it's something that I discover when I have had the assessment conversation with the individual.” (Informant 3) 
The assessment structure helped to highlight the individuals' need for contact and follow-up. The informants described the individuals' need for contact both with the $\mathrm{CM}$ and other team members to prevent hospitalisation:

"The individual needs to feel the security from knowing that there is one person who answers, and if I can't answer, they know that I will call back. They get personal help when they need it. That security, I think is the most important thing really." (Informant 1 )

"Continuity in contact is important, based on the individuals' needs and wishes. Sometimes you may not really see the need to meet this individual every week, but when you try to stretch it out, it does not always work out well. It may be such a thing that keeps them on track, which mitigates hospitalisation, it is important!" (Informant 4)

The informants described the need for meaningful work so that the individual can feel part of a context, which makes the individuals' need for efforts from other societal institutions very real.

"During the assessment conversation, more information may emerge, which in turn can form the basis of care interventions." (Informant 10)

"I think it is very important that the individual has something to do. One can really see the improvement that takes place when they have some work. They get a context to be part of and they feel that they are doing something valuable. Then, they won't be isolated." (Informant 4)

The informants felt that the most important thing about conducting structured assessment conversations was the possibility of evaluating and comparing remission status.

"After the evaluations, we always go through what we have come up with and what is different from last year." (Informant 8)

\subsection{Assessment Process}

Several informants believed that the assessment process itself promotes remission for individuals with schizophrenia. However, it required that the assessment result is really used as a basis for care. Through the process, it became clear which different options and interventions were most suitable for everyone.

"The connection between structured assessment conversation and the individuals' opportunity to reach remission depends on what you do with the assessment conversation. As staff, you get more information, but I think the important thing is what you work with." (Informant 8)

"The most important are the measures that the CM makes after the assessment!" (Informant 1)

The structured process includes, following the individuals' consent, to contact a relative for follow-up of their experience. Thus, the assessment conversation had significance for creating a common agenda and communication channel, 
both in relation to the individual and in contact with their relatives.

"It has happened on some occasions that the father has experienced a high burden as a relative. He is very careful to write what he believes and thinks. Then we have met: the individual, the father and I and we have gone through the situation. That has been a very good assessment, one of the best!" (Informant 8)

The information highlighted by the assessment instruments created a common agenda for the team to start with. Through this part of the process, it became easier for the team to communicate with each other in a clearer and more efficient way.

"I believe that if the individual is to achieve remission, we must have a common planning at an early stage, when something has gone wrong. I think the planning is $\mathrm{A}$ and $\mathrm{Z}$ for the individual; otherwise, there's a risk that some are lost." (Informant 9)

In the third subcategory, the importance of having the "right" team competence to meet the individuals' needs was highlighted, and that the staff turnover at the out-patient psychiatric units, in contrast to the in-patient psychiatric care, being low enough to promote the continuity of care.

"Collaboration within our team takes place in different ways. The formal way is that we discuss the individuals and how they feel at the care conference." (Informant 9)

"Somewhere you must start removing something in the work, when you take in too much new stuff. The question is what to remove, so as not to lower quality. Quality is something you have to protect!' (Informant 3)

\section{Discussion}

\subsection{Discussion of Results}

The result of this study shows that the assessment conversations are considered to promote remission for individuals with schizophrenia. However, this is not the only factor. The informants emphasised the importance of professional competence, that the assessments were structured with correct comparisons of the individuals' status and the process itself where the assessments became the basis for care. These three factors appear to form a causal chain. Competence is a prerequisite for good structure, and the structure affects the process.

The basis is thus, the competence, which, according to the participants, was knowledge and good familiarity with definitions and criteria when evaluating. It was not only basic education that was required, but the necessity of having both specialised medical and nursing knowledge in psychiatric care was emphasised. [35] emphasises that competence in psychiatric care is not just about treating psychosis symptoms, but also about being able to conduct a qualified preventive and health-promoting work. 
To carry out safe and correct assessments of symptoms, function, side effects and the individuals' overall situation, knowledge of the various assessment instruments was required, which included definitions and criteria from which the assessment was based. Competent employees with long experience regularly calibrated the instruments' scale, which contributed to high validity. This fits well with other studies where scales and estimates are used. Sadler et al. [36] emphasise that lack of education, skills and good assessment routines are more common causes of differences in assessments than the deficiencies in the instruments themselves.

Another factor that required competence was the alliance-generating approach. Goss et al. [37] believe that the ability to create alliances and involve individuals' is limited in psychiatric out-patient staff. In a study of 80 visits, psychiatrists showed a lack of ability to engage the individual. The study emphasises that a traditional attitude of "driving over the individual" and that psychiatric "healthcare professionals know best" is an outdated attitude that does not correspond to national healthcare policies [37]. In addition, new care philosophies have an increasing influence on how to relate to the individual. Gabrielsson et al. [38] believe that the concept of person-centred care, i.e. a holistic, individualised, respectful and alliance-generating care, has not received the same influence in psychiatry as in other clinical contexts. The author emphasises that competence in classical sense is not always enough to achieve person centring, it also requires an organisational culture that is shared by the staff. Such a culture involves widespread commitment and willingness to nurturing beneficial therapeutic relationships with the individual.

After competence comes a good assessment structure. The concept of structure can be associated with the fact that there is "order", that is, the work is performed according to good clinical practice. Symptoms and dysfunctions of schizophrenia cannot be measured or assessed in the same way as blood pressure or blood sugar level [39]. The assessment structure must be used repeatedly for reliable results and comparisons over time. According to Clark et al. [39], the challenge is to conceptualise and categorise mental illness. The informants pointed out that a good assessment structure highlighted the individuals' status, situation, and the need for contact and that this, in turn, promoted reciprocity. A well-balanced care based on accurate assessments prevented unnecessary hospitalisations [1].

Assessment structure was followed by the assessment process, which included how the assessments were used. The informants believed that when the assessment results were used as a basis for care, remission was promoted. One of the informants pointed out that the most important thing was what CM did after the assessment. The statement emphasises how competence and structure have influence on the process, which can have an influence on the individuals' remission. It suggests that remission is not a "quick fix" but requires careful and long-term care of competent employees in a favourable health culture. An as- 
sumption, based on the results of this study, is that good continuity and careful accuracy is the explanation for the successes reported from the studied clinic. No less than $38 \%$ more individuals' achieved remission compared to international reports [25] [26] [29].

The value of these assessments is described by [1] who emphasised that there may be a dramatic deterioration of the neurocognitive ability, but through systematic assessment early during the illness, the risks are discovered, and adequate efforts can be put in place if coordination between psychiatric and somatic care is carried out [40]. The assessment itself is also believed to have a therapeutic effect. A previous study [1] showed that multiple self-assessments increase individuals' ability positively and when they conducted repeated self-assessments, their ability to make adequate self-ratings also increased. Our conclusion was that it might be due to training effects from the repeated assessments; specifically, individuals' talents to communicate about their illness and quality of life were promoted. Our assumption is that these results reflect a factor that contributed to remission, but that there are more reasons that are highlighted in this study that are worth exploring further.

The results indicate that successful results depend on the influence of the assessments on the continuous individual work that the CM performs. The assessment can be compared to an annual health check-up with a proper review and evaluation of the parts that affect everyday life and quality of life. Together with the individual, it was estimated if the state had changed in some direction, and the results were compared from year to year [1].

The participants in the study had a remarkably long experience, with 23 - 49 working years. There may be reasons for concern about reports of increasing staff turnover and more difficulties in filling nursing positions in psychiatry. Ong et al. [41] report that there is a shortage of nurses in psychiatry and are questioning why psychiatric nursing not the preferred option for nursing students. This study points in part to the value of the CMs long professional experience and partly that the collaboration between the CM and the individual takes place continuously for joint assessment of the illness condition over time.

\subsection{Strengths and Limitations}

The research issues formed the basis for the choice of method [31]. The starting point was to include informants strategically with both long and short professional experience in psychiatric care. Already during the first interviews, views emerged which far exceeded the expected and which were clearly relevant to the study's results. The data material had so-called strong information power [42]. However, problems arose in including informants with shorter professional experience for two reasons; several CM had stopped their employment at the outpatient clinic and those who have recently worked had not yet been able to learn all the basic tasks.

The informants did not always respond directly to the questions, but all gave detailed descriptions and examples of what promotes remission in their work. 
The validity of the result is strengthened by the quotations reported [32]. The authors repeatedly made sure that subcategories and categories were rooted in the original text, compared and critically examined. To strengthen credibility, the categories were set against the purpose throughout the analysis process [43]. In addition, triangulation was used during the analysis, and "negative cases" were reported, which increases validity in qualitative research [44] [45].

The study's results cannot be generalised to apply to all psychiatric out-patient care. However, the perceptions presented here can be transferred to activities with similar working methods. To deepen the knowledge of what promotes remission, the phenomenon needs to be studied in a larger group of informants in other contexts [32].

\subsection{Conclusion and Implication}

The study highlights success factors that contribute to promoting remission in individuals' with schizophrenia in out-patient psychiatric care. The study shows that the assessment process is of great importance in the remission-promoting work in out-patient psychiatry. It gives CMs and the team a tool to use and support the individuals' to live a healthy life. Regularly, systematic assessments of the patient group stimulate both individuals' and staff to work on health promotion and increase preparedness. It is of great importance that the clinic management creates the conditions for $\mathrm{CM}$ and the team to implement the assessment process, according to all the rules, including education, training and team collaboration.

\section{Acknowledgements}

The authors would like to thank all CM who participated in the study. The study received financial support from the Fyrbodal Research and Development Council, Region Västra Götaland and the Department of Research and Development, the NU-Hospital Organization, Trollhättan, Sweden. The funding sources were not involved in the design, analysis or writing process.

\section{Authors' Contributions}

MO-T, BM, SK, EC, LH and SB-P, all contributed to the study design. The data collection was performed by MO-T and the analysis was mainly carried out by the first author (MO-T) and validated by the last author (SBP) and approved by all authors. The result was discussed by (MO-T, EC, SB-P) until consensus was reached. MO-T wrote the initial draft of the manuscript in close cooperation with SBP, and the manuscript was continuously discussed with EC, in order to perform a critical revision of the manuscript. All authors read and approved the final manuscript.

\section{Conflicts of Interest}

The authors report no conflict of interest. 


\section{References}

[1] Olsson-Tall, M., Hjärthag, F., Marklund, B., Kylén, S., Carlström, C. and Helldin, L. (2019) The Impact of Repeated Assessments by Patients and Professionals: A 4-Year Follow-Up of a Population with Schizophrenia. Journal of the American Psychiatric Nurses Association, 25, 189-199. https://doi.org/10.1177/1078390318777785

[2] Hjärthag, F., Helldin, L., Karilampi, U. and Norlander, T. (2010) Illness-Related Components for the Family Burden off Relatives to Patients with Psychotic Illness in Clinical Practice. Social Psychiatry and Psychiatric Epidemiology, 45, 275-283. https://doi.org/10.1007/s00127-009-0065-x

[3] Hjärthag, F., Helldin, L., Olsson, A.-K. and Norlander, T. (2012) Family Burden and Functional Assessment in the Swedish CLIPS-Study: Do Staff and Relatives Agree on Individuals with Psychotic Disorders' Functional Status? Social Psychiatry and Psychiatric Epidemiology, 47, 581-587. https://doi.org/10.1007/s00127-011-0358-8

[4] Patel, V. and Saxena, S. (2018) Evidence for Action on Mental Health and Global Development. The Lancet, 392, 1553-1598. https://doi.org/10.1016/S0140-6736(18)31612-X

[5] Piccenelli, M. and Gomez Homen, F. (1997) Gender Differences in the Epidemiology of Affective Disorders and Schizophrenia. Division of Mental Health, WHO, Geneva.

[6] World Health Organization (2017) Psychosis, including Schizophrenia. http://www.emro.who.int/health-topics/schizophrenia/index.html

[7] Hjortsberg, C., Helldin, L., Hjärthag, F. and Löthgren, M. (2011) Costs for Patients with Psychotic Illness: Differences Depending upon State of Remission. The Journal of Mental Health Policy and Economics, 14, 87-93. https://europepmc.org/abstract/med/21881164

[8] Kay, S.R., Fiszbein, A. and Opler, L.A. (1987) The Positive and Negative Syndrome Scale (PANSS) for Schizophrenia. Schizophrenia Bullentin, 13, 261-276.

https://doi.org/10.1093/schbul/13.2.261

[9] Green, M.F., Kern, R.S., Braff, D.L. and Mintz, J. (2000) Neurocognitive Deficits and Function Outcome in Schizophrenia: Are We Measuring the "Right Stuff"? Schizophrenia Bulletin, 26, 119-136. https://doi.org/10.1093/oxfordjournals.schbul.a033430

[10] Kring, A.M., Gur, R.E., Blanchard, J.J., Horan, W.P. and Reise, S.P. (2013) The Clinical Assessment Interviews for Negative Symptoms (CAINS): Final Development and Validation. American Journal of Psychiatry, 170, 165-172.

[11] Choi, M. and Kim, H. (2008) The Study on the Effect of the Advocacy of the Mentally Ill: On the Focus Family Adaptability and the Family Cohesion, Perceived Stigma and Coping Method. Social Science Research Review, 24, 249-275.

[12] Chou, K., Shih, Y. and Chang, C. (2012) Psychosocial Rehabilitation Activities, Empowerment, and Quality of Community-Based Life for People with Schizophrenia. Archives of Psychiatric Nursing, 26, 285-294.

https://doi.org/10.1016/j.apnu.2012.04.003

[13] Harvey, P.D., Helldin, L., Bowie, C.R., Heaton, R.K., Olsson, A.-K., Hjärthag, F., Norlander, T. and Pattersson, T.L. (2009) Performance-Based Measurement of Functional Disability in Schizophrenia: A Cross-National Study in the United States and Sweden. American Journal of Psychiatry, 166, 821-827.

[14] American Psychiatric Association (2013) DSM-V Diagnostic and Statistical Manual of Mental Disorder. 5th Edition, American Psychiatric Publishing, Arlington, VA. 
https://doi.org/10.1176/appi.books.9780890425596

[15] Andreasen, N.C., Carpenter, W.T., Kane, J.M., Lasser, R.A., Marder, S.R. and Weinberger, D.R. (2005) Remission in Schizophrenia: Proposed Criteria and Rationale for Consensus. American Journal of Psychiatry, 162, 441-449.

[16] Harvey, P.D. and Pinkham, A. (2015) Impaired Self-Assessment in Schizophrenia: Why Patients Misjudge Their Cognition and Functioning. Current Psychiatry, 14, 53-59.

https://mdedge-files-live.s3.us-east-2.amazonaws.com/files/s3fs-public/issues/article s/053_0415CP_Harvey_FINAL.pdf

[17] Olsson, M., Carlström, C., Marklund, B., Helldin, L. and Hjärthag, F. (2015) Assessment of Distress and Quality of Life: A Comparison of Self-Assessments by Outpatients with a Schizopsychotic Illness and the Clinical Judgment of Nurses. Archives of Psychiatric Nursing, 29, 284-289.

https://doi.org/10.1016/j.apnu.2015.05.001

[18] Burns, T., Catty, J., Dash, M., Roberts, C., Lockwood, A. and Marshall, M. (2007) Use of Intensive Case Management to Reduce Time in Hospital in People with Severe Mental Illness: Systematic Review and Meta-Regression. British Medical Journal, 335, 336. https://doi.org/10.1136/bmj.39251.599259.55

[19] Rotstein, A., Roe, D., Gelkopf, M., Shadmi, E. and Levine, S.Z. (2008) Quality of Life Disparities between Persons with Schizophrenia and Their Professional Caregivers: Network Analysis in a National Cohort. Schizophrenia Research, 197, 109-115. https://doi.org/10.1016/j.schres.2017.12.017

[20] Bäck-Pettersson, S., Sandersson, S. and Hermansson, E. (2014) Patients' Experiences of Supportive Conversation as Long-Term Treatment in a Swedish Psychiatric Outpatient Care Context: A Phenomenological Study. Issues in Mental Health Nursing, 35, 127-133. https://doi.org/10.3109/01612840.2013.860646

[21] Olsson, M., Larsson, L.G., Flensner, G. and Bäck-Pettersson, S. (2012) The Impact of Concordant Communication in Outpatient Care Planning-Nurses' Perspective. Journal of Nursing Management, 20, 748-757. https://doi.org/10.1111/j.1365-2834.2012.01479.x

[22] Orlando, I.J. (1961) The Dynamic Nurse-Patient Relationship, Function, Process and Principles. GP Putnam, New York.

[23] Emsley, R., Chiliza, B., Asmal, L. and Lehloenya, K. (2011) The Concepts of Remission and Recovery in Schizophrenia. Current Opinion in Psychiatry, 24, 114-121.

[24] Laursen, T.M., Wahlbeck, K., Hällgren, J., Westman, J. and Ösby, U. (2013) Life Expectancy and Death by Diseases of the Circulatory System in Patients with Bipolar Disorder or Schizophrenia in the Nordic Countries. PLOS ONE, 8, e67133. https://doi.org/10.1371/journal.pone.0067133

[25] De Hert, M., van Winkel, R., Wampers, M., Kane, K., van Os, J. and Peuskens, J. (2007) Remission Criteria for Schizophrenia: Evaluation in a Large Naturalistic Cohort. Schizophrenia Research, 92, 68-73.

[26] Helldin, L., Kane, J.M., Karilampi, U., Norlander, T. and Archer, T. (2007) Remission in Prognosis of Functional Outcome: A New Dimension in Treatment of Patients with Psychotic Disorders. Schizophrenia Research, 93, 160-168. https://doi.org/10.1016/j.schres.2007.01.014

[27] Lasser, R., Nasrallah, H., Helldin, L., Peuskens, J., Kane, J.M., Docherty, J. and Toledo Tronco, A. (2007) Remission in Schizophrenia: Applying Recent Consensus Criteria to Refine the Concept. Schizophrenia Research, 96, 223-231.

[28] Lindström, E., Wieselgren, I.-M. and von Knorring, L. (1994) Interrater Reliability 
of the Structured Clinical Interview for the Positive and Negative Syndrome Scale for Schizophrenia. Acta Psychiatrica Scandinavica, 89, 192-195. https://doi.org/10.1111/j.1600-0447.1994.tb08091.x

[29] van Os, J., Drukker, M., à Campo, J., Meijer, J., Bak, M. and Delespaul, P. (2006) Validation of Remission Criteria for Schizophrenia. American Journal of Psychiatry, 163, 2000-2002. https://doi.org/10.1176/ajp.2006.163.11.2000 https://ajp.psychiatryonline.org/doi/pdf/10.1176/ajp.2006.163.11.2000

[30] World Medical Association (2018) The Declaration of Helsinki: Ethical Principles for Medical Research Involving Human Subjects.

https://www.wma.net/policies-post/wma-declaration-of-helsinki-ethical-principlesfor-medical-research-involving-human-subjects/

[31] Graneheim, U.H. and Lundman, B. (2004) Qualitative Content Analysis in Nursing Research: Concepts, Procedures and Measures to Achieve Trustworthiness. Nurse Education Today, 24, 105-112. https://doi.org/10.1016/j.nedt.2003.10.001

[32] Graneheim, U., Lindgren, B.-M. and Lundman, B. (2017) Methodological Challenges in Qualitative Content Analysis: A Discussion Paper. Nurse Education Today, 56, 29-34. https://doi.org/10.1016/j.nedt.2017.06.002

[33] Field, A. (2011) Discovering Statistics Using SPSS. 3th Edition, Sage, Thousand Oaks, CA.

[34] Polit, D. and Beck C.T. (2016) Nursing Research. Generating and Assessing Evidence for Nursing Practice. 10th Edition, Lippincott Williams \& Wilkins, Philadelphia, PA.

[35] Lahti, M., Ellilä, H., Jormfeldt, H., Skärsäter, I., Doyle, L., Higgins, A., Keogh, B., Meade, O., Stickley, T., Jan Sitvast, J. and Kilkku, N. (2018) The Required Knowledge for Lifespan Mental Health Promotion and Prevention for Master's Level Mental Health Nurse Education-The eMenthe Project. International Journal of Health Promotion and Education, 56, 143-154. https://doi.org/10.1080/14635240.2018.1431953

[36] Sadler, M.E., Yamamoto, R.T., Khurana, L. and Susan M. Dallabrida, S.M. (2017) The Impact of Rater Training on Clinical Outcomes Assessment Data: A Literature Review. International Journal of Clinical Trials, 4, 1-10. https://doi.org/10.18203/2349-3259.ijct20173133

[37] Goss, C., Moretti, F., Mazzi, M.A., Del Piccolo, L., Rimondini, M. and Zimmermann, C. (2008) Involving Patients in Decisions during Psychiatric Consultations. The British Journal of Psychiatry, 193, 416-421. https://doi.org/10.1192/bjp.bp.107.048728

[38] Gabrielsson, S., Sävenstedt, S. and Zingmark, K. (2015) Person-Centered Care: Clarifying the Concept in the Context of Inpatient Psychiatry. Scandinavian Journal of Caring Sciences, 29, 555-562. https://doi.org/10.1111/scs.12189

[39] Clarke, D.E., Narrow, W.E., Regier, D.A., Kuramoto, S.J., Kupfer, D.J., Kuhl, E.A., Greiner, L. and Kraemer, H.C. (2013) DSM-5 Field Trials in the United States and Canada, Part I: Study Design, Sampling Strategy, Implementation, and Analytic Approaches. American Journal of Psychiatry, 170, 43-58. https://doi.org/10.1176/appi.ajp.2012.12070998

[40] Helldin, L., Hjärthag, F., Olsson, A.-K. and Harvey, P.D. (2015) Cognitive Performance, Symptom Severity, and Survival among Patients with Schizophrenia Spectrum Disorder: A Prospective 15-Year Study. Schizophrenia Research, 169, 141-146. https://doi.org/10.1016/j.schres.2015.09.009

[41] Ong, H.L., Seow, E., Chua, B.Y., Xie, H., Wang, J., Lau, Y.W., Chong, S.A. and Sub- 
ramaniam, M. (2017) Why Is Psychiatric Nursing Not the Preferred Option for Nursing Students: A Cross-Sectional Study Examining Pre-Nursing and Nursing School Factors. Nurse Education Today, 52, 95-102.

https://doi.org/10.1016/j.nedt.2017.02.014

[42] Malterud, K., Siersma, V.D. and Guassora, A.D. (2016) Sample Size in Qualitative Interview Studies: Guided by Information Power. Qualitative Health Research, 26, 1753-1760. https://doi.org/10.1177/1049732315617444

[43] Fatahi, N., Mattsson, B., Lundgren, S.M. and Hellström, M. (2010) Nurse Radiographers' Experiences of Communication with Patients Who Do Not Speak the Native Language. Journal of Advanced Nursing, 66, 774-783.

https://doi.org/10.1111/j.1365-2648.2009.05236.x

[44] Halcomb, E.J. and Andrew, S. (2005) Triangulation as a Method for Contemporary Nursing Research. Nurse Researcher, 13, 71-82.

https://doi.org/10.7748/nr.13.2.71.s8

[45] Streubert, H. and Carpenter, D.R. (2011) Qualitative Research in Nursing: Advancing the Humanistic Imperative. 5th Edition, Wolters Kluwer/Lippincott Williams \& Wilkins, Philadelphia, PA. 